\title{
Central Generation of Grooming Motor Patterns and Interlimb Coordination in Locusts
}

\author{
Ari Berkowitz and Gilles Laurent \\ Division of Biology, California Institute of Technology, Pasadena, California 91125
}

\begin{abstract}
Coordinated bursts of leg motoneuron activity were evoked in locusts with deefferented legs by tactile stimulation of sites that evoke grooming behavior. This suggests that insect thoracic ganglia contain central pattern generators for directed leg movements. Motoneuron recordings were made from metathoracic and mesothoracic nerves, after eliminating all leg motor innervation, as well as all input from the brain, subesophageal ganglion, and prothoracic ganglion. Strong, brief trochanteral levator motoneuron bursts occurred, together with silence of the slow and fast trochanteral depressor motoneurons and activation of the common inhibitor motoneuron. The metathoracic slow tibial extensor motoneuron was active in a pattern
\end{abstract}

distinct from its activity during walking or during rhythms evoked by the muscarinic agonist pilocarpine. Preparations in which the metathoracic ganglion was isolated from all other ganglia could still produce fictive motor patterns in response to tactile stimulation of metathoracic locations. Bursts of trochanteral levator and depressor motoneurons were clearly coordinated between the left and right metathoracic hemiganglia and also between the mesothoracic and the ipsilateral metathoracic ganglia. These data provide clear evidence for centrally generated interlimb coordination in an insect.

Key words: scratching; motor control; insect; thoracic; ganglia; CPG; locomotion
In vertebrates, central pattern generators (CPGs) within the spinal cord can generate basic patterns of motoneuron activity for control of limb movements during locomotion and scratching in the absence of movement-related sensory feedback (Gelfand et al., 1988; Stein, 1989). In insects, however, the presence or role of a CPG(s) for limb motor control has been controversial (Delcomyn, 1980; Pearson, 1985; Bässler, 1986, 1993; Cruse, 1990). Studies of the neural control of insect leg movements have focused primarily on locomotion (Graham, 1985). There have been several reports that decapitated cockroaches with deafferented legs can produce alternating bursts of coxal levator and depressor motoneuron activity (Pearson and Iles, 1970, 1973; Pearson, 1972; Zilber-Gachelin and Chartier, 1973). These rhythms were interpreted as expressions of a CPG for locomotion (Pearson and Iles, 1970; Pearson, 1972; Zilber-Gachelin and Chartier, 1973), but later work suggested that this rhythm might relate to grooming (Reingold and Camhi, 1977) or righting (Zill, 1986) in addition to or instead of locomotion. Recently, rhythms of leg motoneuron activity that are similar to but slower than locomotion have been recorded in isolated thoracic ganglia bathed with the muscarinic agonist pilocarpine (Ryckebusch and Laurent, 1993, 1994; Büschges et al., 1995), but it is not clear whether a pilocarpine bath mimics the natural internal milieu during walking.

Grooming may provide a convenient alternative to locomotion for investigating the neural control of insect leg movements. Grooming (also known as scratching, cleaning, or wiping) involves directed limb movements and can occur in the absence of inputs

\footnotetext{
Received May 15, 1996; revised Aug. 27, 1996; accepted Sept. 20, 1996.

This research was supported by a National Research Service Award Postdoctoral Fellowship to A.B. and a National Science Foundation Presidential Faculty Fellowship to G.L. We thank two anonymous reviewers for helpful comments.

Correspondence should be addressed to Dr. Gilles Laurent, Division of Biology, 139-74, California Institute of Technology, Pasadena, CA 91125.

Dr. Berkowitz' current address: Department of Psychology, UCLA, Los Angeles, CA 90095-1563.

Copyright (C) 1996 Society for Neuroscience $0270-6474 / 96 / 168079-13 \$ 05.00 / 0$
}

from the brain in insects, amphibians, reptiles, and mammals (Rowell, 1961; Eaton and Farley, 1969; Vandervorst and Ghysen, 1980; Stein, 1983; Berkowitz and Laurent, 1996). This behavior is reliably evoked by specific tactile stimuli, even in reduced preparations (Stein, 1983; Berkowitz and Laurent, 1996). In contrast, locomotor patterns in reduced vertebrate preparations often require pharmacological or electrical stimulation (Gelfand et al., 1988). Moreover, several distinct forms of grooming can often be evoked by tactile stimulation of different regions of the body (Stein, 1983), allowing one to study neural mechanisms of behavioral choice (Stein, 1989; Berkowitz and Stein, 1994a,b).

In the companion paper (this issue), we demonstrated that locusts can groom at least four distinct metathoracic and abdominal locations, using a middle leg or hindleg, in the absence of inputs from the brain, subesophageal ganglion, or prothoracic ganglion. A distinct movement strategy and a distinct pattern of muscle activities were used during grooming of each site. In addition, there was suggestive evidence of interlimb coordination during grooming. In the current paper, we investigate patterns of leg motoneuron activity evoked by the same tactile stimuli using a similar paradigm but with all leg motor innervation severed and, thus, in the absence of movement-related sensory feedback. We also examine which ganglia are sufficient to produce these fictive motor patterns and whether the motor patterns exhibit centrally generated interlimb coordination. Some of these data have been previously reported in abstract form (Berkowitz and Laurent, 1995).

\section{MATERIALS AND METHODS}

Dissection. Experiments were performed on male locusts, Schistocerca americana, from a crowded laboratory colony, either in early adulthood $(n=49)$ or in the fifth instar $(n=1)$. Animals were tested with tactile stimulation before dissection; those that did not groom readily were not dissected. For most experiments that did not involve intracellular recording, the locust was placed dorsal side up on a narrow clay platform that supported the head, thorax, and abdomen; the legs were held against the sides of the platform with clay. An opening was cut in the dorsal thoracic 


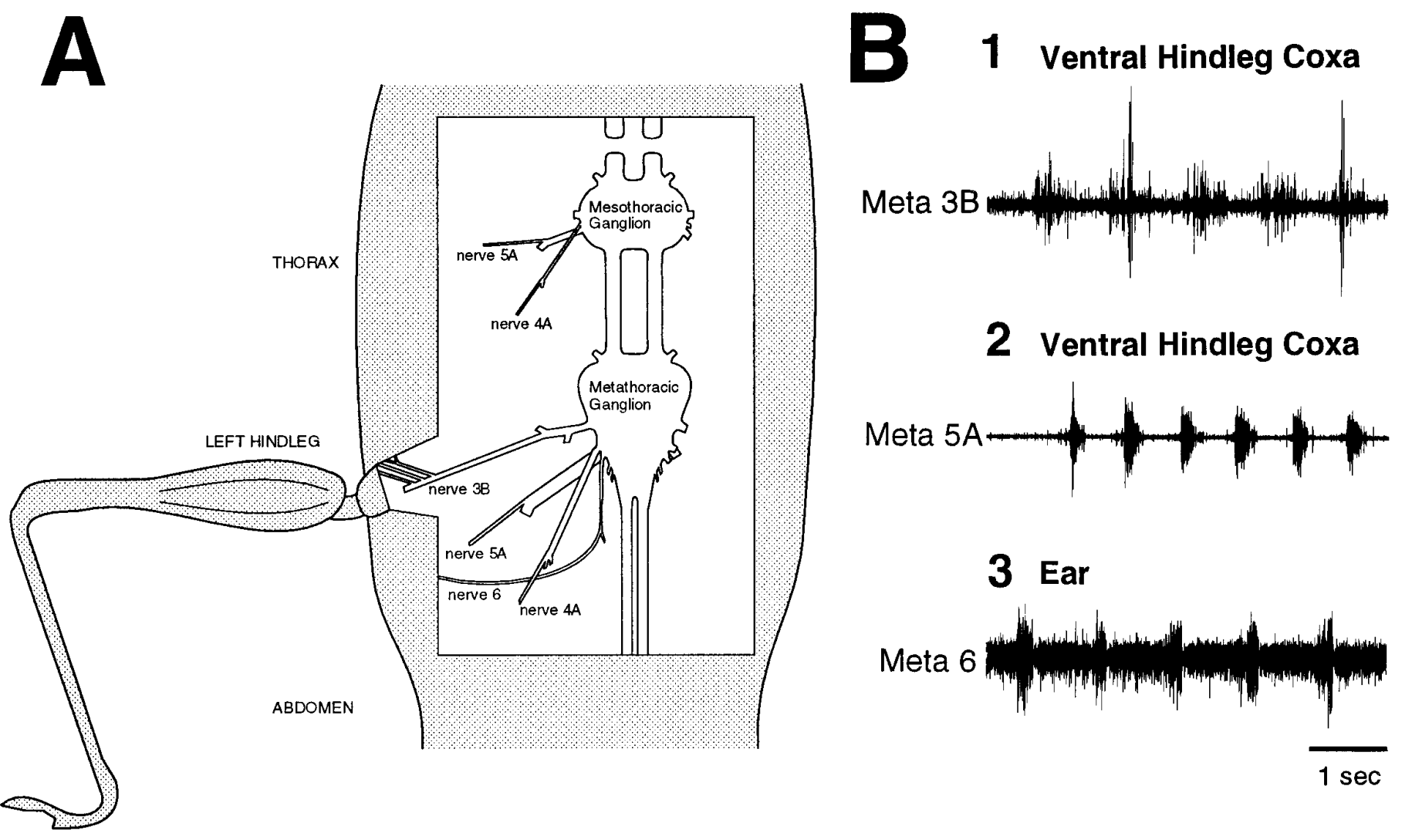

Figure 1. The mesothoracic-abdominal preparation with all leg motor innervation severed. $A$, Schematic illustration of the dissected mesothoracic and metathoracic nerves on one side, viewed from above. The only intact nerve branches were several thin, anterior sensory branches of metathoracic nerve 3B, which provide mechanosensory innervation of the hindleg coxa, and the thick, lateral branch of metathoracic nerve 6 , which provides mechanosensory (and auditory) innervation of the ear. $B$, Sensory responses of nerve branches innervating the hindleg coxa and ear. In each case, the nerve branch was severed, and the distal part was recorded with a suction electrode. Each nerve burst corresponds to one discrete stroke of the fire-polished tip of a glass micropipette (5 strokes in 1; 6 strokes in 2; 5 strokes in 3). 1, Metathoracic nerve 3B recording; the ventral hindleg coxa was stimulated. 2, Metathoracic nerve 5A recording; the ventral hindleg coxa was stimulated. 3 , Metathoracic nerve 6 recording; the ear was stimulated. The recording in 3 was performed in a fifth instar animal in which nerve 6 showed no response to sound.

cuticle, and the gut was tied off with a hair at the anterior and posterior ends of the exposure, severed on the thoracic side of the tie, and removed. The thoracic cavity was then flushed thoroughly with ice-cold locust saline containing (in mM): $140 \mathrm{NaCl}, 5 \mathrm{KCl}, 5 \mathrm{CaCl}_{2}, 4 \mathrm{NaHCO}_{3}, 1 \mathrm{Mg} \mathrm{Cl}_{2}, 6.3$ $\mathrm{N}$-2-hydroxyethylpiperazine- $\mathrm{N}^{\prime}$-2-ethanesulfonic acid, $\mathrm{pH} 7.0$, and $2.5 \%$ dextrose. Cold saline was regularly dripped into the thoracic cavity and drawn off during the dissection. The connectives between the prothoracic and mesothoracic ganglia were severed with fine iridectomy scissors.

Nerve recording. The connective tissue surrounding nerves was stripped away using a fine insect pin. Recordings were obtained from the cut ends of nerve branches using polyethylene suction electrodes or were made en passant with $50 \mu \mathrm{m}$ stainless steel differential hook electrodes (California Fine Wire, Grover Beach, CA). The thoracic cavity was superfused with room-temperature saline throughout recording. All nerve recordings were amplified $(1000 \times)$ and filtered $(0.1-1 \mathrm{kHz}$ bandpass) with a differential AC amplifier (A-M Systems, Everett, WA). Recordings were stored using an eight-channel digital audio tape recorder (MicroData Instrument, Woodhaven, NY) and printed using a Gould TA4000 thermal chart recorder (Gould, Cleveland, $\mathrm{OH}$ ).

Sensory innervation. In one series of experiments $(n=9)$, we determined which metathoracic nerve branches provide mechanosensory innervation of the hindleg coxa and the ear by suction electrode recording from the distal cut ends of nerve branches that had been severed proximally or by en passant recording from selected intact branches. Tactile stimulation was delivered using discrete strokes of a fine paintbrush $(3 / 0)$ or the fire-polished tip of a micropipette. These experiments demonstrated that nerve 3B innervates much of the coxa via several thin distal branches that join the main nerve anteriorly (Fig. 1A,B1), nerve 5A innervates a small region on the ventral surface of the coxa via one of two distal branches (Fig. 1B2), and nerve 6 provides both auditory and mechanosensory innervation of the ear via its thicker, lateral branch (Fig. $1 A, B 3)$. The mechanosensory innervation of the ear was demonstrated by cauterizing or puncturing the ear of adult locusts and finding continued responses to tactile stimulation of the ear and by using a fifth instar animal in which nerve 6 responded to tactile stimulation of the ear but showed no response to sound (Fig. 1B3). These innervation patterns confirm previous findings (Campbell, 1961; Pflüger et al., 1981; Bräunig, 1982). En passant recordings from these nerve branches, when intact, showed no motor activity during grooming motor patterns.

Fictive motor patterns. Patterns of leg motoneuron activity were recorded in the absence of any leg motor innervation in adult locusts $(n=$ 37). All mesothoracic nerves were severed. All metathoracic nerves were severed except the thin, anterior branches of nerve $3 \mathrm{~B}$ and the thick, lateral branch of nerve 6 , which provide mechanosensory innervation to the hindleg coxa and the ear, respectively, but do not contain motoneuron axons (see above). The main branch of metathoracic nerve $3 \mathrm{~B}$ was cut where it enters the coxa, and the proximal cut end was recorded using a suction electrode. This nerve branch contains the axon of the slow tibial extensor motoneuron (SETi), which innervates muscle 135 (Burrows and Hoyle, 1973; Wilson, 1979), as well as the axons of the seven anterior trochanteral levator motoneurons, which innervate muscle 131 (Bräunig, 1982; Siegler and Pousman, 1990) (the numbering of muscles is according to Snodgrass, 1929); extracellularly recorded action potentials of SETi could be distinguished from those of the trochanteral levator motoneurons by the large and consistent size of SETi spikes and the tonic, spontaneous activity that SETi often displayed. The proximal cut ends of metathoracic nerves $4 \mathrm{~A}$ and $5 \mathrm{~A}$ were also recorded simultaneously using suction electrodes. Nerve 4A contains the axons of the six posterior trochanteral levator motoneurons, which innervate muscle 132 (Bräunig, 1982; Siegler and Pousman, 1990); nerve 5A contains the axons of only 
three motoneurons, the slow $\left(D_{s}\right)$ and fast $\left(D_{f}\right)$ trochanteral depressors, which innervate muscle 133a (Bräunig, 1982; Siegler and Pousman, 1990), and the common inhibitor (CI) motoneuron, which innervates a large number of muscles and also has an axon in nerves $3 \mathrm{~B}$ and $4 \mathrm{~A}$ (Bräunig, 1982; Hale and Burrows, 1985). The extracellularly recorded action potentials of these three motoneurons could be distinguished by their relative sizes. The proximal cut ends of mesothoracic nerves $3 \mathrm{~B}, 4 \mathrm{~A}$, and $5 \mathrm{~A}$ were recorded with suction electrodes in some experiments. Mesothoracic nerves $3 \mathrm{~B}$ and $4 \mathrm{~A}$ contain the axons of the 3 anterior and the 11 posterior trochanteral levator motoneurons, respectively (Campbell, 1961; Bräunig, 1982); the axon of mesothoracic SETi is in nerve 5 (Wilson, 1979); mesothoracic nerve $5 \mathrm{~A}$ contains the axons of mesothoracic $\mathrm{D}_{\mathrm{s}}, \mathrm{D}_{\mathrm{f}}$, and CI (Campbell, 1961; Bräunig, 1982; Hale and Burrows, 1985). The connectives between the mesothoracic and metathoracic ganglia and/or between the metathoracic and abdominal ganglia were severed in some experiments, as noted. To provide stability, all legs were held with clay against the sides of the platform, except the $\operatorname{leg}(\mathrm{s})$ associated with the recorded nerves, which was allowed to dangle over the side of the platform; no leg movements were observed in these animals. Fictive motor patterns were elicited by rubbing the tip of a fine paintbrush $(3 / 0)$ continuously back and forth across a $2-5 \mathrm{~mm}$ region of the body surface at $1-4 \mathrm{~Hz}$ for up to $1 \mathrm{~min}$. The posterior abdomen, the ventral or posterior hindleg coxa, the ear, and the anterior hindleg coxa were stimulated; identical tactile stimulation of these sites elicits grooming leg movements when motor innervation is intact (Berkowitz and Laurent, 1996).

Intracellular recordings. Intracellular recordings were obtained from the metathoracic SETi $(n=3)$ and a trochanteral levator motoneuron with its axon in nerve $3 \mathrm{~B}(n=1)$. These experiments were performed on adult locusts, ventral side up; all legs were held down with clay. The connectives between the prothoracic and mesothoracic ganglia were severed. All mesothoracic and metathoracic nerves were either crushed with forceps repeatedly or severed except metathoracic nerve 6. A stainless steel platform was held under the metathoracic ganglion. A small crystal of protease (type XIV, Sigma, St. Louis, MO) was placed onto the anteriorlateral quadrant of the ventral surface of the metathoracic ganglion for 1 min; the thoracic cavity was then flushed thoroughly with cold saline. Intracellular recordings were obtained using 40-80 $\mathrm{M} \Omega$ glass microelectrodes filled with $3 \mathrm{M}$ potassium acetate and amplified $(10 \times)$ using an Axoclamp-2A DC amplifier (Axon Instruments, Burlingame, CA). The proximal cut end of the ipsilateral metathoracic nerve $3 \mathrm{~B}$ was recorded simultaneously using a suction electrode. Confirmation that the intracellularly recorded motoneuron sent an axon through nerve $3 \mathrm{~B}$ was obtained by using intracellularly recorded action potentials to trigger an oscilloscope display of both channels. Fictive motor patterns were elicited by stimulating the posterior abdomen or the ear, as described above.

\section{RESULTS}

\section{Tactually elicited motor patterns in the absence of leg motor innervation}

Tactile stimulation of the posterior abdomen (Fig. 2), the ventral or posterior hindleg coxa (Fig. 3), the ear (Fig. 4), or the anterior hindleg coxa (Fig. 5) evoked coordinated bursts of metathoracic (Figs. $2-4 ; n=13$ ) or mesothoracic (Fig. $5 ; n=2$ ) leg motoneuron activity in nerves $3 \mathrm{~B}, 4 \mathrm{~A}$, and $5 \mathrm{~A}$ in animals in which the connectives between the prothoracic and mesothoracic ganglia and all motor innervation of the legs had been severed. No middle leg or hindleg movements were observed. Motor patterns usually occurred in the metathoracic nerves during stimulation of the posterior abdomen, ventral hindleg coxa, and ear and in the mesothoracic nerves during stimulation of the anterior hindleg coxa, but mesothoracic motor patterns also could occur during stimulation of the posterior abdomen, ventral hindleg coxa, or ear. Both metathoracic and mesothoracic fictive motor patterns consisted of large, sudden bursts of action potentials in the trochanteral levator motoneurons (levators), simultaneously in nerves $3 \mathrm{~B}$ and $4 \mathrm{~A}$, each burst lasting $\sim 1 \mathrm{sec}$. Either one or a series of levator bursts could occur; these bursts could begin as soon as $1.1 \mathrm{sec}$ (Fig. 2) or as late as $32.5 \mathrm{sec}$ (Fig. 3) after the onset of tactile stimu- lation. When there was a series of levator bursts, the bursts did not generally occur in a regular rhythm.

The slow trochanteral depressor motoneuron $\left(\mathrm{D}_{\mathrm{s}}\right)$ in nerve $5 \mathrm{~A}$ was often spontaneously active at a low rate in these preparations and increased its rate of tonic activity during and after tactile stimulation (Figs. 3, 4). During the large levator bursts, $D_{\mathrm{s}}$ and the fast trochanteral depressor motoneuron $\left(\mathrm{D}_{\mathrm{f}}\right)$ in nerve $5 \mathrm{~A}$ were completely inactive (Figs. 2-5). $\mathrm{D}_{\mathrm{s}}$ and $\mathrm{D}_{\mathrm{f}}$ usually exhibited increased activity just before each levator burst and always exhibited increased activity after each levator burst (Figs. 2-5). The CI, visible in nerve $5 \mathrm{~A}$ recordings, was activated almost exclusively during the large levator bursts (Figs. 2-5).

The metathoracic SETi, in nerve $3 \mathrm{~B}$, was spontaneously active at a low rate in some preparations and usually showed increased tonic activity during tactile stimulation. In addition, SETi was active at a higher rate just before and after levator bursts. SETi tended to show increased activity when $D_{s}$ and $D_{f}$ showed increased activity, but SETi could be active at a high rate just before the onset of a levator burst, after $\mathrm{D}_{\mathrm{s}}$ and $\mathrm{D}_{\mathrm{f}}$ had ceased firing (Fig. $3 B$, first cycle, and Fig. 4). It was not possible to monitor SETi activity during the large levator bursts using extracellular recording alone, because the SETi spikes in nerve 3B were masked by levator spikes.

\section{Metathoracic SETi activity during trochanteral levator bursts}

To determine whether SETi is active during the large levator bursts, intracellular recordings from metathoracic SETi and extracellular recordings from the ipsilateral metathoracic nerve $3 \mathrm{~B}$ were made simultaneously $(n=3)$. SETi was active during weak levator bursts (i.e., when only the smallest nerve $3 \mathrm{~B}$ levator motoneurons were active) (Fig. 6A) and was also active at the beginning and end of large levator bursts (Fig. 6B) but was inactive during the strongest levator activity (Fig. $6 B$ ). The timing of SETi activity during these tactually elicited fictive motor patterns was thus distinct from the timing of activity of either the large levator motoneurons or $\mathrm{D}_{\mathrm{s}}$ and $\mathrm{D}_{\mathrm{f}}$.

In one preparation, an intracellular recording was obtained from a metathoracic trochanteral levator motoneuron that gave rise to one of the smallest extracellularly recorded nerve $3 \mathrm{~B}$ spikes (Fig. 6C,D). This small levator motoneuron generated action potentials during weak levator bursts (Fig. 6C) but was silent during the strongest levator activity (Fig. 6D). The timing of its spike activity was thus similar to that of SETi and distinct from that of the large levator motoneurons.

\section{Tactually elicited fictive motor patterns in further reduced preparations}

To determine which parts of the CNS are sufficient to generate these tactually elicited fictive motor patterns, metathoracic nerves $3 \mathrm{~B}, 4 \mathrm{~A}$, and $5 \mathrm{~A}$ were recorded in animals in which the connectives were severed between the mesothoracic and metathoracic ganglia and/or between the metathoracic and abdominal ganglia (in addition to severing the connectives between the prothoracic and mesothoracic ganglia and severing all leg motor innervation). Metathoracic-abdominal preparations (connectives severed just anterior to the metathoracic ganglion; $n=2$ ) could generate fictive motor patterns in response to stimulation of the posterior abdomen, the ventral hindleg coxa, or the ear (data not shown). Metathoracic-alone preparations (connectives severed just anterior and posterior to the metathoracic ganglia; $n=3$ ) could generate fictive motor patterns in response to stimulation of the 


\section{POSTERIOR ABDOMEN}

Figure 2. Fictive motor pattern evoked by tactile stimulation of the posterior abdomen in a mesothoracicabdominal preparation. Each trace is a suction electrode recording from the proximal part of a severed metathoracic nerve branch; all nerves were recorded ipsilateral to the stimulated location. $A$ shows the motor pattern at a slow time scale; $B$ shows the initial part of the motor pattern, indicated by a thick, horizontal bar, at a faster time scale. Up and down arrows indicate the beginning and end of tactile stimulation. Tactile stimulation consisted of continuous rubbing at $1-4 \mathrm{~Hz}$ with the tip of a fine paintbrush; there was no correspondence between the frequency of rubbing and the frequency of motoneuron bursts. Motoneurons are identified by the relative sizes of their extracellularly recorded action potentials (see Materials and Methods). The first large burst of trochanteral levator motoneurons began $1.1 \mathrm{sec}$ after the onset of tactile stimulation. Troch Lev, Trochanteral levator motoneurons; SETi, slow tibial extensor motoneuron; $D$, slow trochanteral depressor motoneuron; $D_{f}$, fast trochanteral depressor motoneuron; $C I$, common inhibitor motoneuron. Note that coordinated hindleg motoneuron bursts were evoked by tactile stimulation of the posterior abdomen in the absence of leg movement.

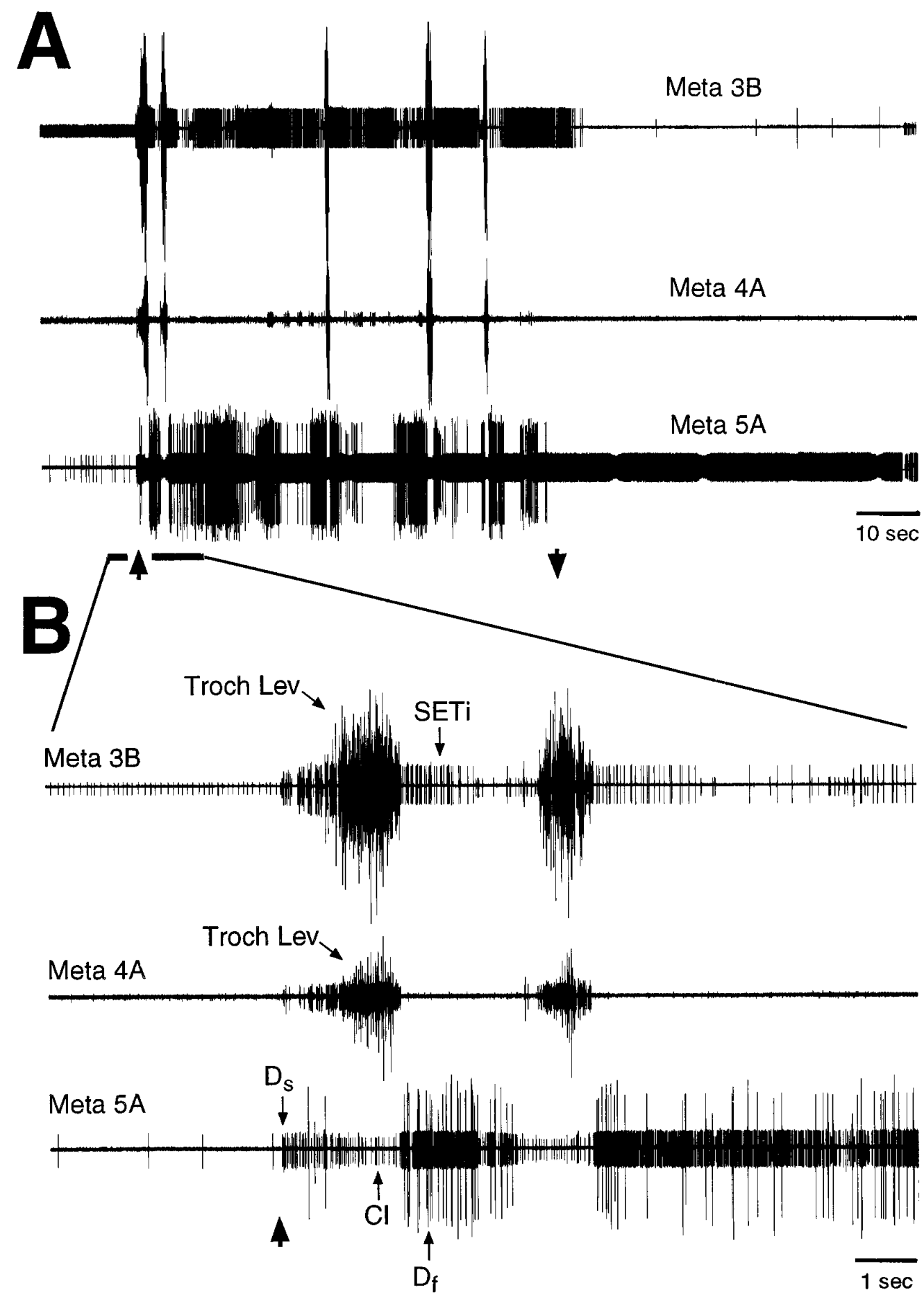

ventral hindleg coxa or the ear (Fig. 7), as could mesothoracicmetathoracic preparations (connectives severed just anterior to the mesothoracic ganglion and just posterior to the metathoracic ganglion; $n=8$ ) (data not shown). In addition, single spontaneous levator bursts occurred occasionally in all types of preparations; these spontaneous levator bursts were accompanied by SETi, $\mathrm{D}_{\mathrm{s}}$, $\mathrm{D}_{\mathrm{f}}$, and $\mathrm{CI}$ activity similar to that which occurred during tactually elicited motor patterns (Fig. 7A).

\section{Centrally generated coordination between left and right hindlegs}

To test for centrally generated coordination between the sets of motoneurons controlling the two hindlegs, left and right metathoracic nerves $4 \mathrm{~A}$ and $5 \mathrm{~A}$ were recorded in mesothoracic-abdominal preparations with all leg motor innervation severed $(n=3)$. These preparations exhibited clear coordination of left and right motoneuron bursts both during spontaneous levator bursts (Fig. 


\section{VENTRAL HINDLEG COXA}

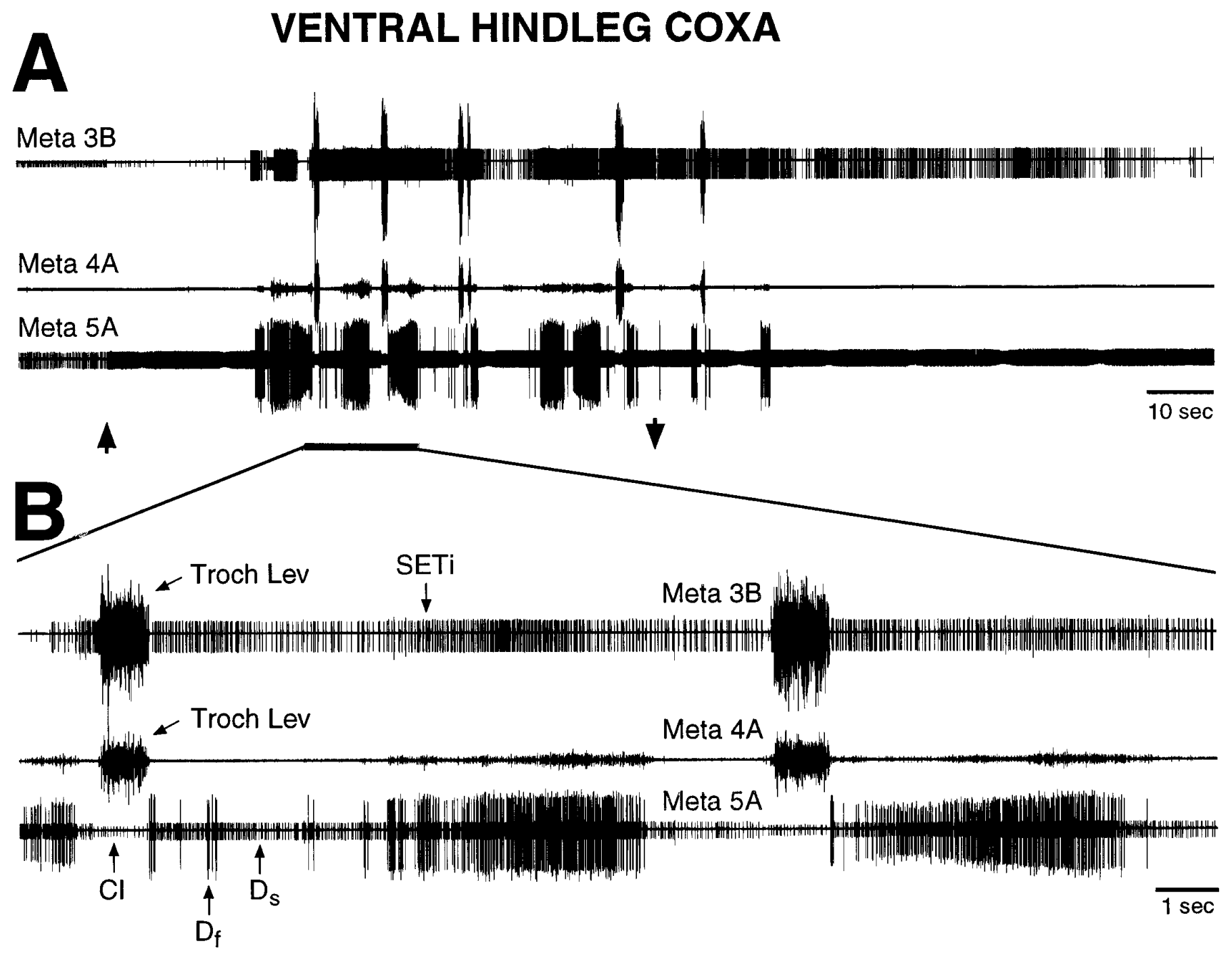

Figure 3. Fictive motor pattern evoked by tactile stimulation of the ventral hindleg coxa in a mesothoracic-abdominal preparation. $A$ shows the motor pattern at a slow time scale; $B$ shows part of the motor pattern at a faster time scale. The first large burst of trochanteral levator motoneurons began 32.5 $\mathrm{sec}$ after the onset of tactile stimulation. These recordings are from the same preparation as shown in Figure 2; conventions are as in Figure 2. Note that coordinated hindleg motoneuron bursts were evoked by tactile stimulation of the ventral hindleg coxa in the absence of leg movement.

$8 A$ ) and during tactually elicited fictive motor patterns (Fig. $8 B, C)$. In by far the most common type of coordination, each nerve $4 \mathrm{~A}$ levator burst was accompanied by a simultaneous contralateral nerve $5 \mathrm{~A}$ depressor burst and, often, activity of small nerve 4A motoneurons as well (Fig. 8B). In a few instances, a very different type of coordination occurred: the left and right nerve 4A levators burst simultaneously, along with the left and right CIs, whereas all nerve 5A depressors were silenced (Fig. 8C, asterisk); these synchronous levator bursts occurred during a period when levator bursts exhibiting the more common type of coordination also occurred (Fig. 8C).

\section{Centrally generated coordination between middle leg and hindleg}

To test for centrally generated coordination between the sets of motoneurons controlling the middle leg and ipsilateral hindleg, mesothoracic and ipsilateral metathoracic nerves 4A and 5A were recorded in mesothoracic-abdominal preparations with all leg motor innervation severed $(n=6)$. These preparations exhibited clear coordination of mesothoracic and metathoracic motoneuron bursts both spontaneously (Fig. 9A,B) and during tactually elicited fictive motor patterns (Fig. 9C,D). Three distinct types of mesothoracic-metathoracic coordination were observed. Each type involved simultaneous activation of excitatory motoneurons in two or three of the four nerves recorded. The most common pattern consisted of a nerve 4A levator burst, along with activation of $\mathrm{CI}$ and silence of $\mathrm{D}_{\mathrm{s}}$ and $\mathrm{D}_{\mathrm{f}}$, in one ganglion and a simultaneous burst of $\mathrm{D}_{\mathrm{s}}$ and $\mathrm{D}_{\mathrm{f}}$ in the adjacent ganglion (Fig. $9 \mathrm{C}$ ); activity of small motoneurons in nerve $4 \mathrm{~A}$ of the adjacent ganglion sometimes occurred as well (Fig. 9C). This type of coordination was analogous to the most common type of left-right metathoracic coordination (Fig. 8B). A second pattern involved relatively strong simultaneous activation of nerve $4 \mathrm{~A}$ levators and $\mathrm{D}_{\mathrm{s}}$ and $\mathrm{D}_{\mathrm{f}}$ in one ganglion, along with weak nerve $4 \mathrm{~A}$ activity in the adjacent ganglion; this pattern commonly occurred spontaneously (Fig. $9 A, B)$. A third pattern involved simultaneous activation of $\mathrm{D}_{\mathrm{s}}$ and $\mathrm{D}_{\mathrm{f}}$ in both ganglia, along with activation of small nerve $4 \mathrm{~A}$ motoneurons in one of the ganglia (Fig. 9D). 
EAR

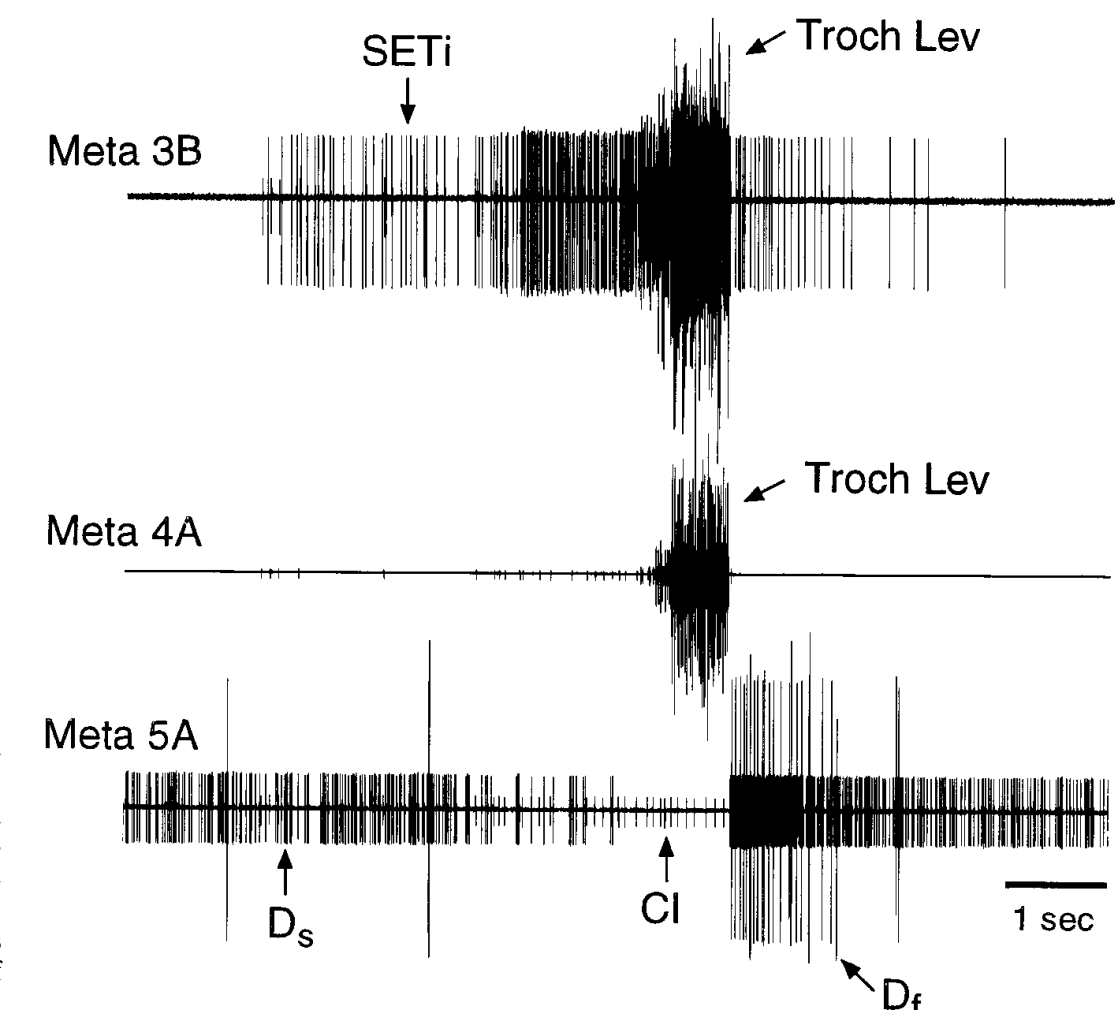

Figure 4. Fictive motor pattern evoked by tactile stimulation of the ear in a mesothoracic-abdominal preparation. Tactile stimulation began before the period illustrated and continued throughout this period. The large burst of trochanteral levator motoneurons began $10.4 \mathrm{sec}$ after the onset of tactile stimulation. Conventions are as in Figure 2. Note that the coordinated hindleg motoneuron burst was evoked by tactile stimulation of the ear in the absence of leg movement.

\section{DISCUSSION}

\section{Central generation of grooming motor patterns}

In this study, coordinated leg motoneuron bursts were evoked by tactile stimulation of thoracic and abdominal sites in a locust preparation with all leg motor innervation severed. These fictive motor patterns may be expressions of CPGs used to generate grooming movements by the hindleg or the middle leg. The fictive motor patterns were evoked using tactile stimuli identical to those that evoke actual grooming leg movements in a similar preparation (compare Berkowitz and Laurent, 1996). There were some differences, however, between grooming movements and the fictive motor patterns. When a series of cycles occurred, the movement cycles were generally more frequent and more regular than the fictive cycles. The lower frequency of fictive cycles may be a consequence of the extensive loss of tonic sensory inputs caused by the dissection. Deafferentation in many systems reduces the frequency of movement cycles or fictive cycles, perhaps because it reduces the tonic excitation delivered to the CNS (Wilson, 1961; Delcomyn, 1980). Lack of regularity in the timing of levator bursts was also observed during fictive rhythms in cockroaches with deafferented legs (Pearson, 1985). Fictive locomotor or scratching motor patterns in limbed vertebrates, in contrast, are quite regular (Gelfand et al., 1988; Stein, 1989). Thus, it is possible that CPGs are more important for the regularity of leg motor bursts in vertebrates than in insects.

There were no obvious and reliable differences among the metathoracic fictive motor patterns evoked by stimulation of the posterior abdomen, ventral hindleg coxa, and ear, although clear differences were evident in the hindleg grooming movements and electromyograms (EMGs) for these three locations (Berkowitz and Laurent, 1996). Thus, additional tonic sensory inputs (the preparation was largely deafferented) and/or movement-related phasic sensory inputs may be necessary for generation of complete and site-specific motor patterns. In contrast, fictive motor patterns for turtle scratching display site-specific coordination of knee and hip motoneurons and are virtually identical to EMGs during actual scratching of those sites (Mortin et al., 1985; Robertson et al., 1985). Thus, movement-related sensory feedback may be more important for grooming in insects than in vertebrates.

Trochanteral levators and depressors, respectively, raise and lower the locust femur. A key question is whether the tactually elicited fictive motor patterns include activity in motoneurons that control other joints, particularly the tibia, and whether there is coordination of motoneurons controlling different leg joints. During pilocarpine-evoked rhythms in the locust metathoracic ganglion, bursts of the SETi occur only during trochanteral depressor bursts (Ryckebusch and Laurent, 1993). This pattern is similar to that observed during actual locomotion in locusts; the metathoracic SETi is active almost exclusively during the hindleg stance phase of walking when the hindleg femur is depressed (Burns and Usherwood, 1979). In contrast, during the tactually elicited fictive motor patterns studied here, the timing of SETi activity was similar to that of a small trochanteral levator motoneuron; SETi was active during depressor bursts and during weak levator bursts as well as at the beginning and end of some strong levator bursts. This suggests that the tactually elicited fictive motor patterns are distinct from both walking motor patterns and pilocarpine-evoked rhythms. The same or overlapping networks of central neurons might nonetheless be used to generate grooming and walking movements of the middle leg and hindleg. Sensory and/or neuromodulatory inputs might modify the basic motor output to suit each behavior (Dickinson, 1995; Katz, 1995). Heitler (1995) has 


\section{ANTERIOR HINDLEG COXA}

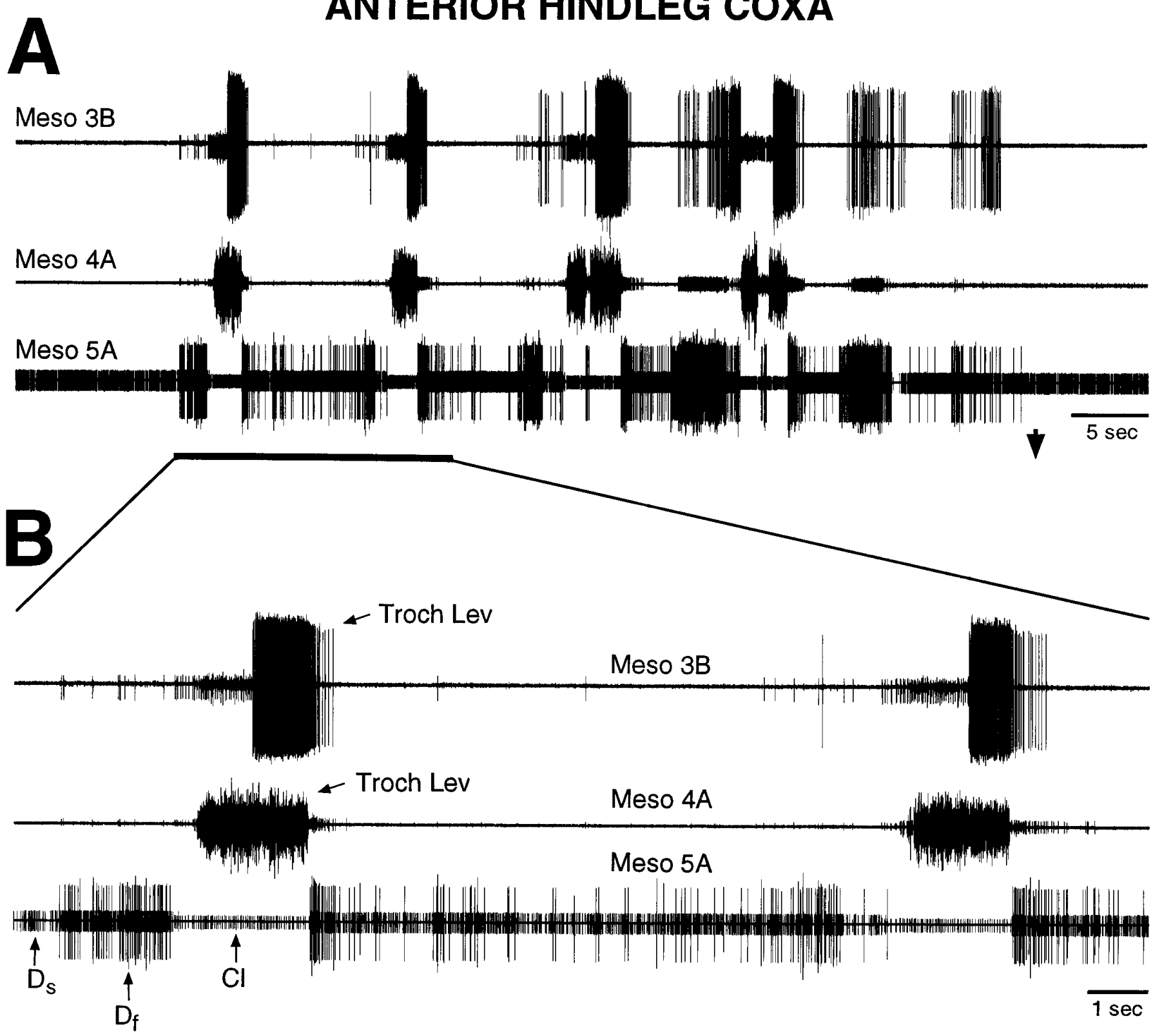

Figure 5. Fictive motor pattern evoked by tactile stimulation of the anterior hindleg coxa in a mesothoracic-abdominal preparation. Each trace is a suction electrode recording from the proximal end of a cut mesothoracic nerve branch; all nerves were recorded ipsilateral to the stimulated location. $A$ shows the motor pattern at a slow time scale; $B$ shows part of the motor pattern at a faster time scale. Tactile stimulation began before the period illustrated. The first large burst of trochanteral levator motoneurons began $27.6 \mathrm{sec}$ after the onset of tactile stimulation. Other conventions are as in Figure 2. Note that coordinated middle leg motoneuron bursts were evoked by tactile stimulation of the anterior hindleg coxa in the absence of leg movement.

shown recently that the basic motor pattern for locust hindleg kicking is also centrally generated.

\section{Comparison with other fictive motor patterns for insect leg movements}

There is a long history of debates about whether insect limb locomotor movements are controlled by chain reflexes or CPGs (Roeder, 1937; Wilson, 1966; Pearson and Iles, 1970, 1973; Pearson, 1972; Zilber-Gachelin and Chartier, 1973; Delcomyn, 1980; Bässler and Wegner, 1983; Pearson, 1985; Bässler, 1986, 1993; Cruse, 1990; Ryckebusch and Laurent, 1993, 1994; Büschges et al., 1995). It is clear that the vertebrate spinal cord can generate basic patterns of limb motoneuron activity for locomotion and scratching, even without movement-related sensory feedback (Gelfand et al., 1988; Stein, 1989). This has been conveniently demonstrated by recording fictive motor patterns in animals injected with a nicotinic acetylcholine receptor antagonist, which blocks vertebrate neuromuscular transmission and, hence, prevents all movement (Gelfand et al., 1988; Stein, 1989). One reason for the controversy over insect limb motor control may be technical; the insect neuromuscular junction is glutamatergic, not cholinergic (Gration et al., 1979), and no glutamatergic antagonist effective at the insect neuromuscular junction has yet been identified. Thus, it 

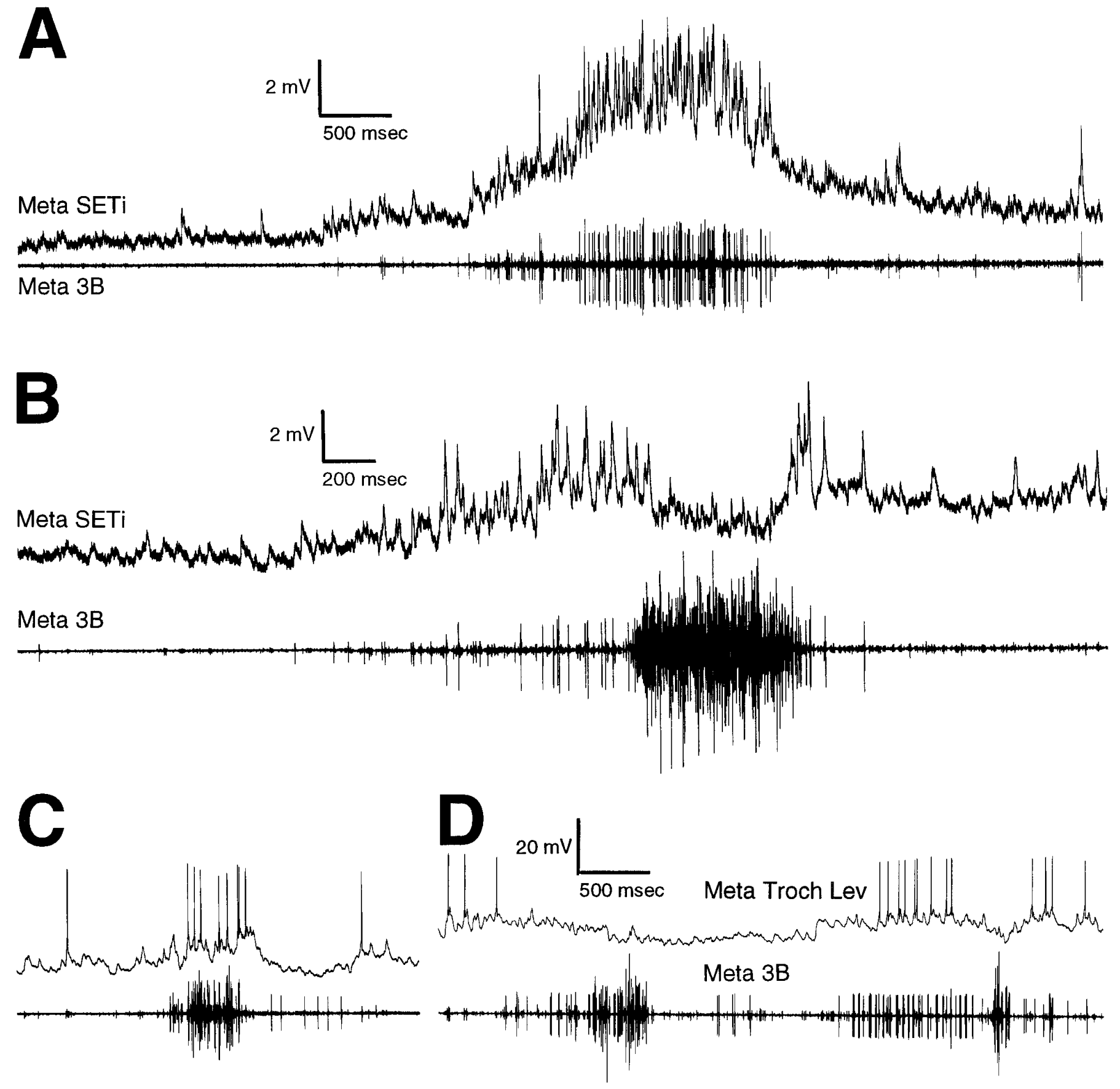

Figure 6. Intracellular motoneuron recordings during tactually elicited fictive motor patterns in mesothoracic-abdominal preparations. $A, B$, Metathoracic SETi intracellular recording and simultaneous ipsilateral metathoracic nerve 3B recording. SETi spikes can be seen in both the intracellular and the extracellular recording. $A$, SETi activity during a weak trochanteral levator burst; the posterior abdomen was stimulated. $B, \mathrm{SETi}$ activity during a strong trochanteral levator burst; the posterior abdomen was stimulated. $A$ and $B$ are from the same preparation. $C, D$, Intracellular recording from a metathoracic trochanteral levator motoneuron with an axon in nerve 3B (small unit). $C$, Activity of the trochanteral levator during a weak, spontaneous levator burst. $D$, Activity of the levator during two strong levator bursts evoked by stimulation of the posterior abdomen.

has been necessary to use (1) deafferented preparations to prevent phasic feedback during leg movement (Pearson and Iles, 1970, 1973; Pearson, 1972; Zilber-Gachelin and Chartier, 1973; Bässler and Wegner, 1983), (2) deefferented preparations to prevent all leg movement (this study), or (3) completely isolated CNSs with pharmacological induction of motor patterns (Ryckebusch and Laurent, 1993, 1994; Büschges et al., 1995).

A decapitated cockroach, pinned on its back and with all legs deafferented, can generate alternating bursts of activity in metathoracic (hindleg) coxal levator and depressor motoneurons; this was interpreted as the expression of a CPG for walking (Pearson and Iles, 1970, 1973; Pearson, 1972; Zilber-Gachelin and Chartier, 1973). Comparisons of leg EMGs during several types of behavior in the intact cockroach, however, suggested that the motor patterns recorded in the deafferented preparation may be related to grooming or righting in addition to or instead of locomotion 
A Spontaneous
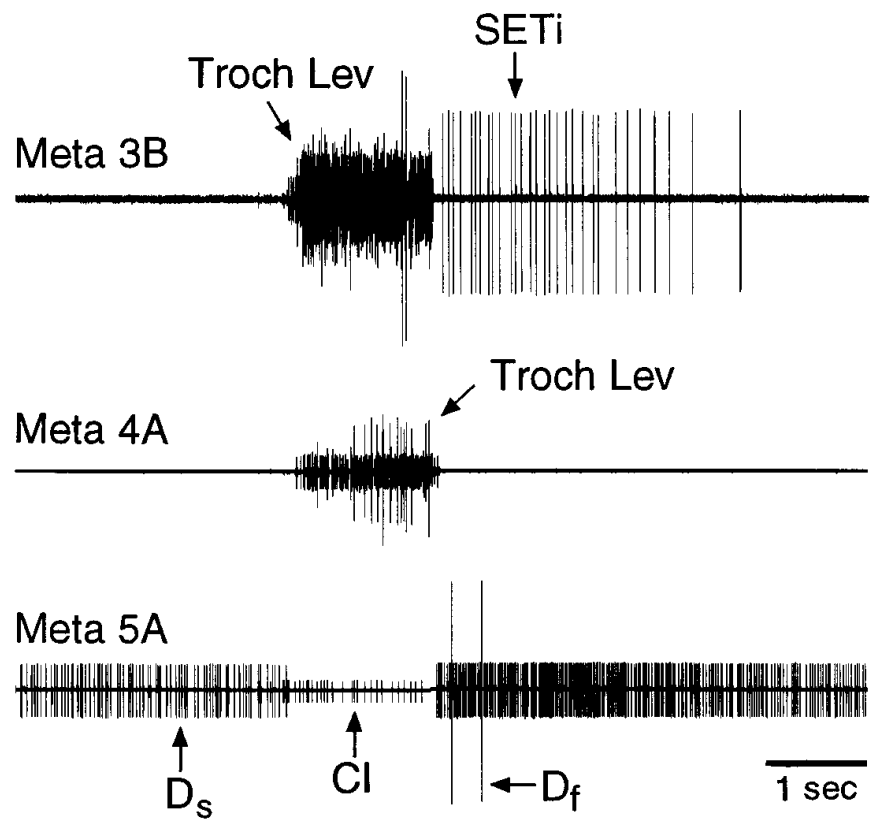

Ear

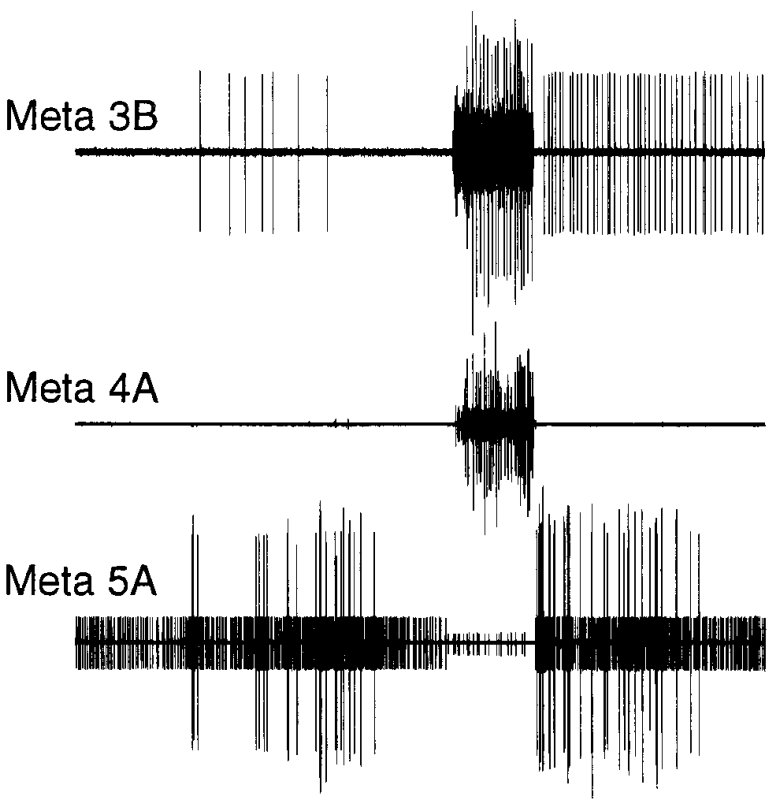

\section{Ventral Hindleg Coxa}
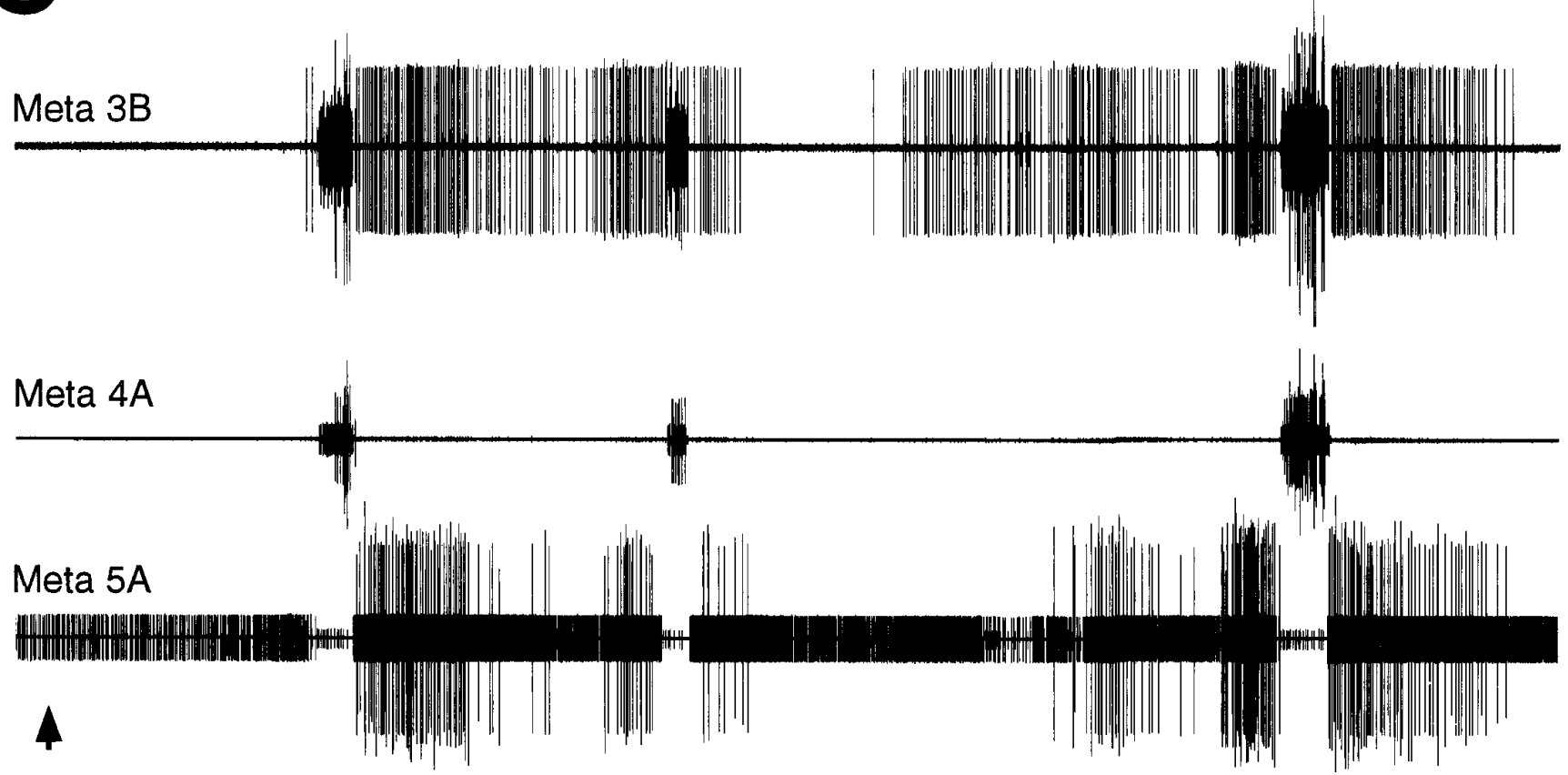

Figure 7. Spontaneous and tactually elicited fictive motor patterns evoked in a metathoracic-alone preparation. The connectives were severed just anterior to and just posterior to the metathoracic ganglion. $A$, Spontaneous motor pattern. $B$, Motor pattern during tactile stimulation of the ear. Tactile stimulation began before the period illustrated and continued throughout this period. The large levator burst began $21.3 \mathrm{sec}$ after the onset of tactile stimulation. $C$, Motor pattern during tactile stimulation of the ventral hindleg coxa. The first large levator burst began 3.2 sec after the onset of tactile stimulation. Conventions are as in Figure 2.

(Reingold and Camhi, 1977; Sherman et al., 1977; Zill, 1986). Stick insects with denervated thoracic ganglia also can produce bursts of motor activity in response to abdominal stimulation, but coordination of this motor activity is poor; the activity was thought to underlie rocking or irregular seeking leg movements (Bässler and Wegner, 1983). Some have questioned whether centrally generated rhythms in insect leg motoneurons play an important role in any actual behavior (Pearson, 1985; Bässler, 1986, 1993; 
A

L Meta 4A
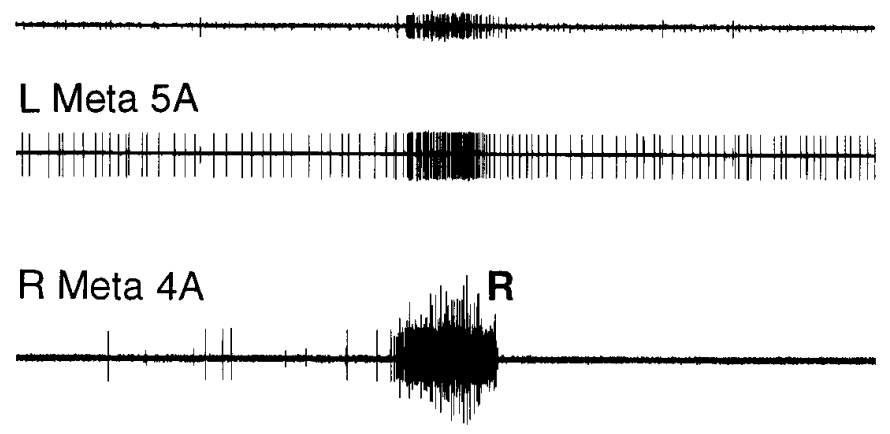

R Meta 5A
C

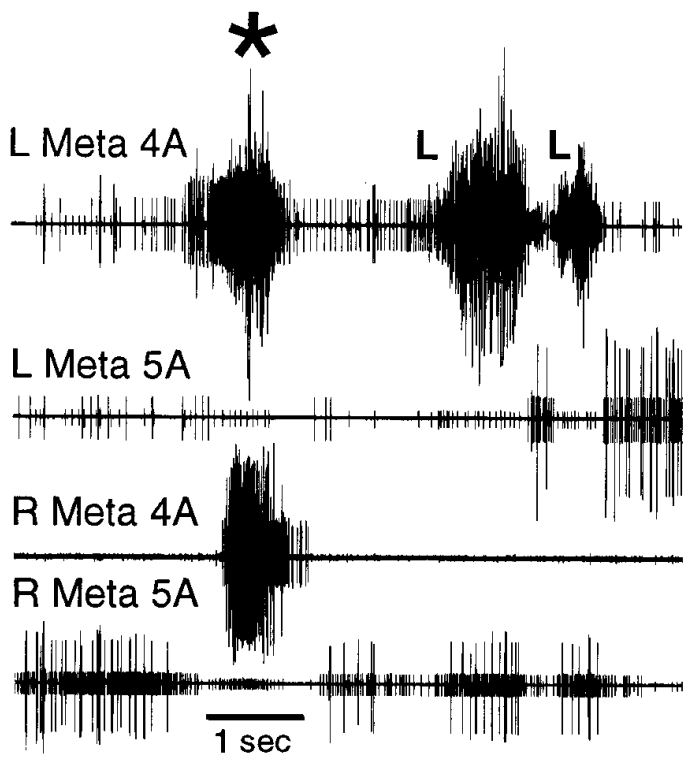

1 sec

B

L Meta 4A
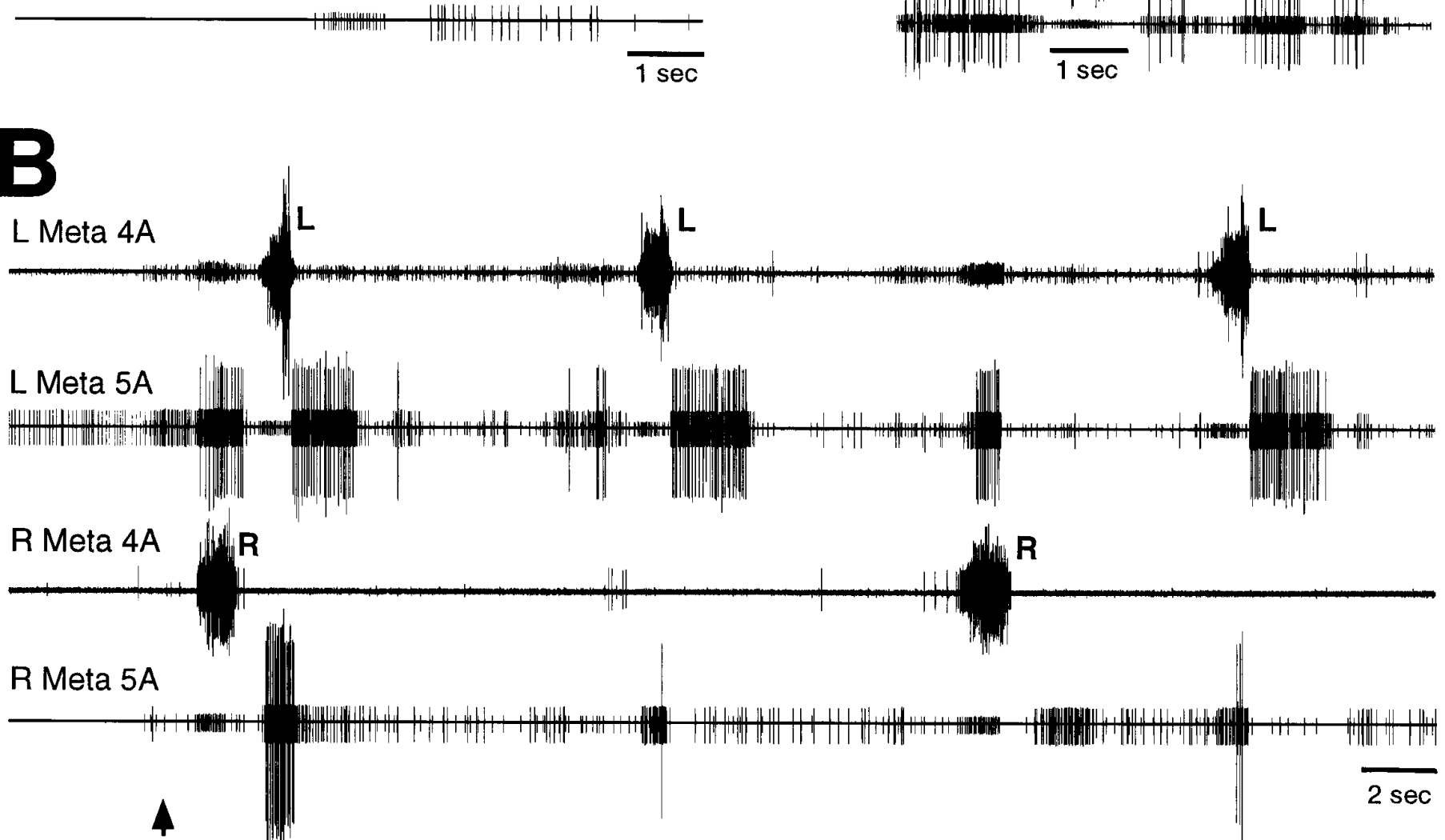

$\mathbf{R}$

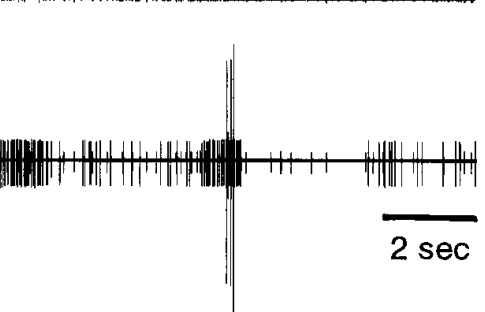

Figure 8. Coordination between left and right metathoracic motoneuron bursts during fictive motor patterns in a mesothoracic-abdominal preparation. $A$, Spontaneous motor pattern. $B$, Examples of the most common type of coordination during tactile stimulation of the left ear. The first large levator burst began $0.9 \mathrm{sec}$ after the onset of tactile stimulation. $C$, Example of synchronous left and right levator bursts during tactile stimulation of the right ear. Tactile stimulation began before the period illustrated and continued throughout this period. The first large levator burst began 10.4 sec after the onset of tactile stimulation. $L$ and $R$ indicate left and right trochanteral levator bursts, respectively, with simultaneous activation of the contralateral trochanteral depressors. Asterisk indicates synchronous levator bursts. Other conventions are as in Figure 2.

Cruse, 1990). Recently, patterns of leg motoneuron activity similar to but slower than locomotor patterns have been recorded from locust and later stick insect thoracic ganglia bathed in the muscarinic agonist pilocarpine (Ryckebusch and Laurent, 1993, 1994; Büschges et al., 1995). The mechanism(s) of pilocarpine activation of rhythmic activity are not known, and it is not yet clear whether similar mechanisms are used during actual locomotion in the absence of exogenous drugs. The current study further demonstrates that fictive motor patterns linked to actual insect leg movements can occur in vivo and without application of exogenous drugs.

\section{Local CPGs for grooming}

The metathoracic ganglion in vivo, isolated from all other ganglia and in the absence of leg motor innervation, was sufficient to produce coordinated bursts of leg motoneuron activity in response to tactile stimulation of the ventral hindleg coxa or the ear. This suggests that the metathoracic ganglion contains CPG cir- 

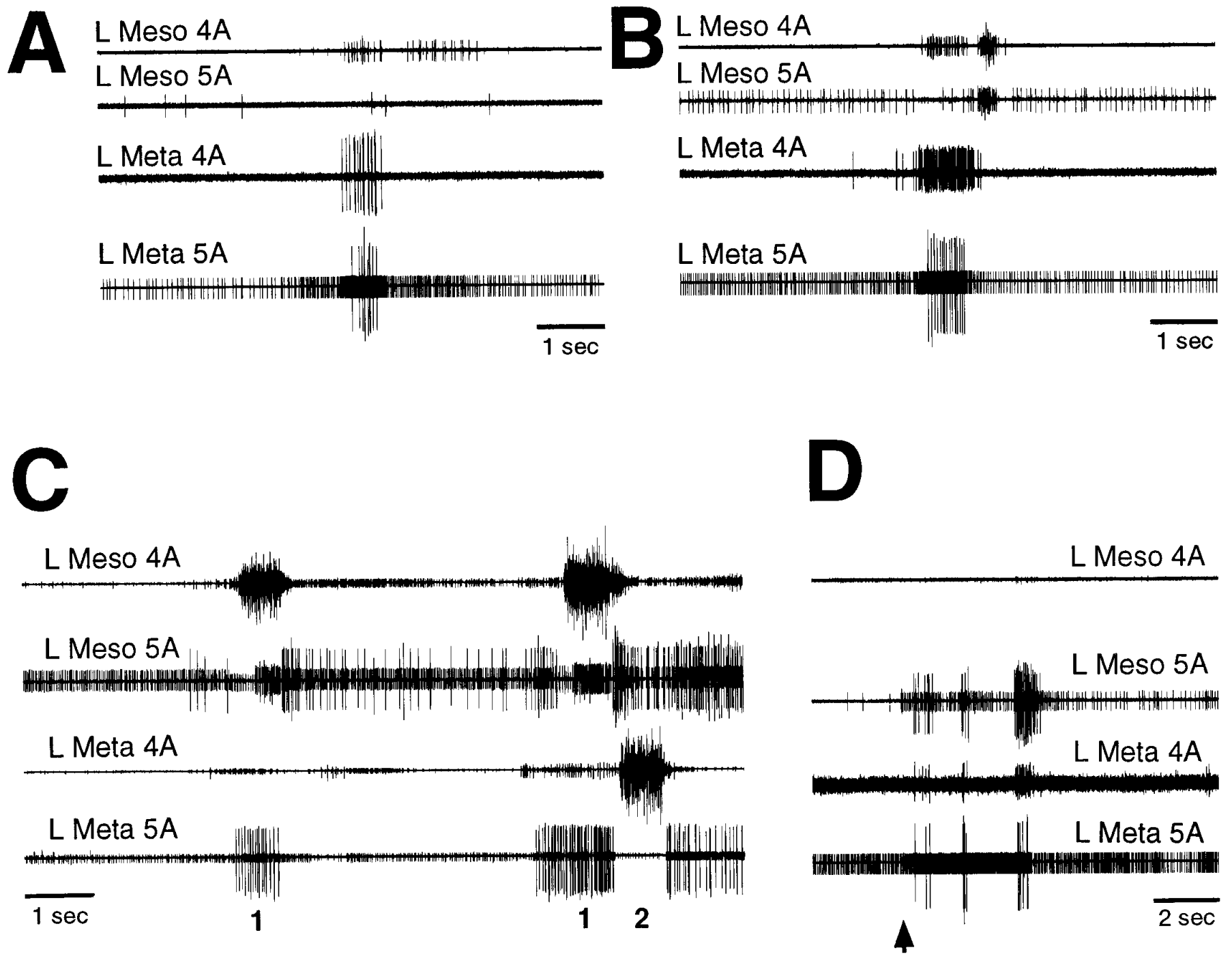

Figure 9. Coordination between mesothoracic and ipsilateral metathoracic motoneuron bursts during fictive motor patterns in mesothoracic-abdominal preparations. $A, B$, Examples of one type of coordination during spontaneous motor patterns. $C$, Examples of another type of coordination (the most common type) during tactile stimulation of the posterior abdomen. Mesothoracic and metathoracic trochanteral levator bursts are indicated by 1 and 2 , respectively; in each case, the trochanteral depressors in the ipsilateral adjacent ganglion were simultaneously activated. Tactile stimulation began before the period illustrated and continued throughout this period. The first large levator burst began $18.9 \mathrm{sec}$ after the onset of tactile stimulation. $D$, Examples of a third type of coordination during tactile stimulation of the left anterior hindleg coxa. The first $\mathrm{D}_{\mathrm{f}}$ burst began $0.4 \mathrm{sec}$ after the onset of tactile stimulation. $A, B$, and $D$ are from the same preparation. Meso, Mesothoracic. Other conventions are as in Figure 2.

cuits that may be used in the generation of grooming movements of the hindleg. When the connections between the mesothoracic and metathoracic ganglia were intact, the preparation could produce coordinated bursts of mesothoracic leg motoneuron activity in response to tactile stimulation of the anterior hindleg coxa (innervated by branches of a metathoracic nerve) that were similar to the metathoracic motor patterns produced during stimulation of the ventral hindleg coxa, ear, and posterior abdomen. This suggests that the mesothoracic ganglion contains CPG circuits for control of the middle leg, similar to the metathoracic circuits for control of the hindleg. An isolated segment of the spinal cord can also generate a fictive rhythm for grooming in turtles (Mortin and Stein, 1989) and cats (Deliagina et al., 1983), although preparations with additional segments intact produce better rhythms (Berkinblit et al., 1978; Deliagina et al., 1983; Mortin and Stein, 1989).

\section{Centrally generated interlimb coordination Coordination between hindlegs}

Bursts of motoneuron activity were clearly coordinated between the left and right hindlegs in the complete absence of leg motor innervation, in vivo, and without exogenous drug application. This may be the strongest evidence to date that there are central neural mechanisms for coordination of left and right legs within an insect thoracic ganglion; it adds to the evidence of pilocarpine-evoked in vitro rhythms in locusts and stick insects (Ryckebusch and Laurent, 1993, 1994; Büschges et al., 1995). In contrast, Pearson and Iles (Pearson and Iles, 1973) and Pearson (Pearson, 1985) stated that there was no clear coordination of motoneurons on opposite sides of a thoracic ganglion in decapitated cockroaches with deafferented legs. In the stick insect with deafferented legs, leftright coordination occurred during weak motoneuron bursts but not during strong bursts (Bässler and Wegner, 1983). Grooming 
by a hindlimb has also been shown to involve contralateral neural circuitry in turtles (Currie and Stein, 1989; Berkowitz and Stein, 1994a,b; Stein et al., 1995) and cats (Arshavsky et al., 1978; Deliagina et al., 1981; O’Donovan et al., 1982; Barajon et al., 1992); hip flexor bursts for the two hindlimbs usually alternate.

Two distinct types of coordination between motoneurons for the two hindlegs were seen here. Most commonly, a trochanteral levator burst was accompanied by a burst of the contralateral trochanteral depressors. This appears to be the same type of coordination seen in pilocarpine-evoked rhythms in locusts (Ryckebusch and Laurent, 1993, 1994). In addition, contralateral nerve 4A motoneurons with small extracellular spikes often were simultaneously active. Assuming that these contralateral nerve 4A motoneurons are trochanteral levators, this represents not only centrally generated interlimb coordination but also centrally generated coactivation of antagonistic levator and depressor motoneurons for a single leg. Weak coactivation of functional antagonists may serve to stiffen an adjacent limb and thus hold it steady during a grooming movement. Coactivation of trochanteral levator and depressor muscles occurs during hindleg grooming of the ear (Berkowitz and Laurent, 1996). Alternatively, it is possible that these small nerve 4A signals actually originated in other nerve 4 branches and were passively conducted along nerve $4 \mathrm{~A}$; motoneuron axons in other nerve 4 branches innervate a wide variety of muscles (Siegler and Pousman, 1990). A second, rarer type of coordination involved synchronous bursts of left and right metathoracic trochanteral levator motoneurons, along with synchronous activation of the left and right metathoracic CI motoneurons. This type of coordination may underlie the synchronous movements of the two hindlegs that were occasionally observed during hindleg grooming (Berkowitz and Laurent, 1996). Synchronous movements of the two hindlimbs can also occur during turtle grooming of caudal regions (Field, 1995). Protractor motoneuron bursts (which move the femur forward) for the two hindlegs of the stick insect also tend to occur in-phase in pilocarpine-evoked rhythms, where they were the only type of left-right central coordination observed (Büschges et al., 1995).

\section{Coordination between middle leg and ipsilateral hindleg}

Bursts of middle leg and ipsilateral hindleg motoneurons often showed clear coordination as well, in the complete absence of leg motor innervation, in vivo, and without exogenous drug application. This may be the strongest evidence to date for centrally generated interganglionic coordination in insect leg motor control; it adds to evidence from cockroaches with deafferented legs (Pearson and Iles, 1973) and pilocarpine-evoked rhythms in locusts and stick insects (Ryckebusch and Laurent, 1994; Büschges et al., 1995).

Three distinct types of coordination were observed between mesothoracic and ipsilateral metathoracic motoneurons. Most commonly, a trochanteral levator burst in either the mesothoracic or metathoracic ganglion was accompanied by a simultaneous trochanteral depressor burst in the ipsilateral adjacent ganglion. This may be the expression of a central mechanism for maintaining stability of the body during elevation of a leg. When one leg is lifted to perform grooming, depressors of the ipsilateral adjacent leg may be activated to keep the adjacent leg on the ground. Depression of an ipsilateral adjacent leg simultaneous with elevation of a grooming leg has been observed in locusts (Berkowitz and Laurent, 1996). This central mechanism might be used for locomotion as well (Ryckebusch and Laurent, 1994). A similar type of coordination has been seen in the cockroach with deaf- ferented legs (Pearson and Iles, 1973) and in the pilocarpinebathed locust preparation (Ryckebusch and Laurent, 1994). In the case of the cockroach, however, only levator motoneurons were recorded; levator bursts in ipsilateral adjacent ganglia were negatively correlated (Pearson and Iles, 1973). The two other types of interganglionic coordination observed in the current study both involved coactivation of trochanteral levators and depressors for a single leg. During movements of one leg, coactivation of functional antagonists for an adjacent leg may serve to increase stiffness of the adjacent leg, also improving stability.

Thus, centrally generated levator bursts may occur in either the mesothoracic or the metathoracic ganglion in response to specific tactile stimuli, and these fictive motor patterns may be coordinated between adjacent legs. These findings raise the possibility that central mechanisms of behavioral choice and central mechanisms of interlimb coordination both can be conveniently studied in this preparation. There are fibers in the connectives between the mesothoracic and metathoracic ganglia that discharge rhythmically during levator bursts in the cockroach (Pearson and Iles, 1973). Intersegmental interneurons that could mediate selection or coordination have been identified in locust mesothoracic and metathoracic ganglia (Laurent, 1986; Laurent and Burrows, 1988). Grooming has been a useful behavior for studying the neural basis of behavioral choice in turtles (Mortin et al., 1985; Robertson et al., 1985; Stein et al., 1986; Currie and Stein, 1989; Stein, 1989; Berkowitz and Stein, 1994a,b). The wealth of knowledge available regarding the anatomical and physiological organization of the locust thoracic ganglia (Burrows, 1992) makes the thoracic control of locust grooming a promising system for investigating the cellular basis of insect limb motor control.

\section{REFERENCES}

Arshavsky YI, Gelfand IM, Orlovsky GN, Pavlova GA (1978) Messages conveyed by spinocerebellar pathways during scratching in the cat. II. Activity of neurons of the ventral spinocerebellar tract. Brain Res 151:493-506.

Barajon I, Gossard JP, Hultborn H (1992) Induction of fos expression by activity in the spinal rhythm generator for scratching. Brain Res 588:168-172.

Bässler U (1986) On the definition of central pattern generator and its sensory control. Biol Cybern 54:65-69.

Bässler U (1993) The walking- (and searching-) pattern generator of stick insects, a modular system composed of reflex chains and endogenous oscillators. Biol Cybern 69:305-317.

Bässler U, Wegner U (1983) Motor output of the denervated thoracic ventral nerve cord in the stick insect Carausius morosus. J Exp Biol 105:127-145.

Berkinblit MB, Deliagina TG, Feldman AG, Gelfand IM, Orlovsky GN (1978) Generation of scratching. I. Activity of spinal interneurons during scratching. J Neurophysiol 41:1040-1057.

Berkowitz A, Laurent G (1995) Central generation of directed limb movements in locusts. Soc Neurosci Abstr 21:1764.

Berkowitz A, Laurent G (1996) Local control of leg movements and motor patterns during grooming in locusts. J Neurosci 16:8067-8078.

Berkowitz A, Stein PSG (1994a) Activity of descending propriospinal axons in the turtle hindlimb enlargement during two forms of fictive scratching: broad tuning to regions of the body surface. J Neurosci 14:5089-5104.

Berkowitz A, Stein PSG (1994b) Activity of descending propriospinal axons in the turtle hindlimb enlargement during two forms of fictive scratching: phase analyses. J Neurosci 14:5105-5119.

Bräunig P (1982) The peripheral and central nervous organization of the locust coxo-trochanteral joint. J Neurobiol 13:413-433.

Burns MD, Usherwood PNR (1979) The control of walking in Orthoptera. II. Motor neurone activity in normal free-walking animals. J Exp Biol 79:69-98.

Burrows M (1992) Local circuits for the control of leg movements in an insect. Trends Neurosci 15:226-232. 
Burrows M, Hoyle G (1973) Neural mechanisms underlying behavior in the locust Schistocerca gregaria. III. Topography of limb motorneurons in the metathoracic ganglion. J Neurobiol 4:167-186.

Büschges A, Schmitz J, Bässler U (1995) Rhythmic patterns in the thoracic nerve cord of the stick insect induced by pilocarpine. $\mathrm{J}$ Exp Biol 198:435-456.

Campbell JI (1961) The anatomy of the nervous system of the mesothorax of Locusta migratoria migadorioides R \& F Proc Zool Soc Lond 137:403-432.

Cruse H (1990) What mechanisms coordinate leg movement in walking arthropods? Trends Neurosci 13:15-21.

Currie SN, Stein PSG (1989) Interruptions of fictive scratch motor rhythms by activation of cutaneous flexion reflex afferents in the turtle. J Neurosci 9:488-496.

Delcomyn F (1980) Neural basis of rhythmic behavior in animals. Science 210:492-498.

Deliagina TG, Orlovsky GN, Perret C (1981) Efferent activity during fictitious scratch reflex in the cat. J Neurophysiol 45:595-604.

Deliagina TG, Orlovsky GN, Pavlova GA (1983) The capacity for generation of rhythmic oscillations in distributed in the lumbosacral spinal cord of the cat. Exp Brain Res 53:81-90.

Dickinson PS (1995) Interaction among neural networks for behavior. Curr Opin Neurobiol 5:792-798.

Eaton RC, Farley RD (1969) The neural control of cercal grooming behaviour in the cockroach, Periplaneta americana. J Insect Physiol 15:1047-1065.

Field EC (1995) Spinal cord control of hindlimb coordination in the turtle. PhD dissertation, Washington University, St. Louis.

Gelfand IM, Orlovsky GN, Shik ML (1988) Locomotion and scratching in tetrapods. In: Neural control of rhythmic movements in vertebrates (Cohen AH, Rossignol S, Grillner S, eds), pp 167-199. New York: Wiley.

Graham D (1985) Pattern and control of walking in insects. Adv Insect Physiol 18:31-140.

Gration KAF, Clark RB, Usherwood PNR (1979) Three types of L-glutamate receptor on junctional membrane of locust muscle fibres. Brain Res 171:360-364.

Hale JP, Burrows M (1985) Innervation patterns of inhibitory motor neurones in the thorax of the locust. J Exp Biol 117:401-413.

Heitler WJ (1995) Quasi-reversible photo-axotomy used to investigate the role of extensor muscle tension in controlling the kick motor programme of grasshoppers. Eur J Neurosci 7:981-992.

Katz PS (1995) Intrinsic and extrinsic neuromodulation of motor circuits. Curr Opin Neurobiol 5:799-808.

Laurent G (1986) Thoracic intersegmental interneurones in the locust with mechanoreceptive inputs from a leg. J Comp Physiol [A] 159:171-186.

Laurent G, Burrows M (1988) A population of ascending intersegmental interneurones in the locust with mechanosensory inputs from a hind leg. J Comp Neurol 275:1-12.

Mortin LI, Stein PSG (1989) Spinal cord segments containing key elements of the central pattern generators for three forms of scratch reflex in the turtle. J Neurosci 9:2285-2296.

Mortin LI, Keifer J, Stein PSG (1985) Three forms of the scratch reflex in the spinal turtle: movement analyses. J Neurophysiol 53:1501-1516.

O'Donovan MJ, Pinter MJ, Dum RP, Burke RE (1982) Actions of FDL and FHL muscles in intact cats: functional dissociation between anatomical synergists. J Neurophysiol 47:1126-1143.

Pearson KG (1972) Central programming and reflex control of walking in the cockroach. J Exp Biol 56:173-193.

Pearson KG (1985) Are there central pattern generators for walking and flight in insects? In: Feedback and motor control in invertebrates and vertebrates (Barnes WJP, ed), pp 307-315. London: Croom Helm.
Pearson KG, Iles JF (1970) Discharge patterns of coxal levator and depressor motoneurones of the cockroach, Periplaneta americana. J Exp Biol 52:139-165.

Pearson KG, Iles JF (1973) Nervous mechanisms underlying intersegmental co-ordination of leg movements during walking in the cockroach. J Exp Biol 58:725-744.

Pflüger HJ, Bräunig P, Hustert R (1981) Distribution and specific central projections of mechanoreceptors in the thorax and proximal leg joints of locusts. II. The external mechanoreceptors: hair plates and tactile hairs. Cell Tissue Res 216:79-96.

Reingold SC, Camhi JM (1977) A quantitative analysis of rhythmic leg movements during three different behaviors in the cockroach, Periplaneta americana. J Insect Physiol 23:1407-1420.

Robertson GA, Mortin LI, Keifer J, Stein PSG (1985) Three forms of the scratch reflex in the spinal turtle: central generation of motor patterns. J Neurophysiol 53:1517-1534.

Roeder KD (1937) The control of tonus and locomotor activity in the praying mantis (Mantis religiosa L.). J Exp Zool 76:353-374.

Rowell CHF (1961) The structure and function of the prothoracic spine of the desert locust, Schistocerca gregaria Forskal. J Exp Biol 38:457-469.

Ryckebusch S, Laurent G (1993) Rhythmic patterns evoked in locust leg motor neurons by the muscarinic agonist pilocarpine. J Neurophysiol 69:1583-1595.

Ryckebusch S, Laurent G (1994) Interactions between segmental leg central pattern generators during fictive rhythms in the locust. J Neurophysiol 72:2771-2785.

Sherman E, Novotny M, Camhi JM (1977) A modified walking rhythm employed during righting behavior in the cockroach Gromphadorhina portentosa. J Comp Physiol [A] 113:303-316.

Siegler MVS, Pousman CA (1990) Motor neurons of grasshopper metathoracic ganglion occur in stereotypic anatomical groups. J Comp Neurol 297:298-312.

Snodgrass RE (1929) The thoracic mechanism of a grasshopper, and its antecedents. Smithson Misc Collect 82:1-111.

Stein PSG (1983) The vertebrate scratch reflex. Symp Soc Exp Biol 37:383-403.

Stein PSG (1989) Spinal cord circuits for motor pattern selection in the turtle. Ann NY Acad Sci 563:1-10.

Stein PSG, Camp AW, Robertson GA, Mortin LI (1986) Blends of rostral and caudal scratch reflex motor patterns elicited by simultaneous stimulation of two sites in the spinal turtle. J Neurosci 6:2259-2266.

Stein PSG, Victor JC, Field EC, Currie SN (1995) Bilateral control of hindlimb scratching in the spinal turtle: contralateral spinal circuitry contributes to the normal ipsilateral motor pattern of fictive rostral scratching. J Neurosci 15:4343-4355.

Vandervorst P, Ghysen A (1980) Genetic control of sensory connections in Drosophila. Nature 286:65-67.

Wilson DM (1961) The central nervous control of flight in a locust. J Exp Biol 38:471-490.

Wilson DM (1966) Insect walking. Annu Rev Entomol 11:103-122.

Wilson JA (1979) The structure and function of serially homologous leg motor neurons in the locust. I. Anatomy. J Neurobiol 10:41-65.

Zilber-Gachelin NF, Chartier MP (1973) Modification of the motor reflex responses due to repetition of the peripheral stimulus in the cockroach. II. Conditions of activation of the motoneurones. J Exp Biol 59:383-403.

Zill SN (1986) A model of pattern generation of cockroach walking reconsidered. J Neurobiol 17:317-328. 